\title{
Drudgery Reduction for Increasing Efficiency of Farm Women Using Hanging Grain Cleaner: A Case of Eco-friendly Method in Wheat Cleaning and Grading
}

\author{
Barkha Sharma $^{1}$, Shilpi Verma ${ }^{2 *}$,S.K. Pandey ${ }^{3}$ and Jagdish Patidar ${ }^{4}$ \\ ${ }^{1}$ (Home Science), KVK Ratlam, Madhya Pradesh, India \\ ${ }^{2}$ (Home Science) KVK Neemuch, Madhya Pradesh, India \\ ${ }^{3}$ SMS (Agril. Extension) KVK Ratlam, Madhya Pradesh, India \\ ${ }^{4}$ SRF (NICRA Project) KVK Ratlam, Madhya Pradesh, India \\ *Corresponding author
}

\section{A B S T R A C T}

Keywords

Drudgery reduction, Heart rate, Ergonomic evaluation

Article Info

Accepted:

12 December 2017

Available Online:

10 January 2018
The present study was planned to assess the drudgery and postural discomfort level on the performance of hanging grain cleaner in comparison to the traditional sieve. Thirty farm women of adopted villages of KVK Ratlam were randomly selected for the study. The results of the study indicated that the amount of energy consumed or spent by the farm women were observed to be lower while performing selected activities with the improved technologies as compared to the adopted traditional methods. It was also found that with the help of modified technology, the work output was more. The respondents reported that the cleaning and grading activity was moderate in term of perceived rate of exertion as compared to be heavy in case of traditional sieve.

\section{Introduction}

Women demonstrate important role in crop production, horticulture, animal husbandry, post-harvest operation, fisheries and etc. Women are doing $70 \%$ of major farm work and constitute $60 \%$ of the farming population. (NSWF, 2014).

In India, agriculture work is primarily done by women. There are about more than 20 million women working in agriculture field out of which $90 \%$ live in villages. The involvement of village women for agricultural work is well known. Farm women thus lead a very hard life. (Suma Haslkar et al., 2005)

After the crop is threshed, all the external impurities like straw, sand, stones, etc are removed from grain by the methods of sieving, winnowing or hand picking. In manual winnowing a person stands with a basket full of grain held over head and tossed during period of fast winds. Wholes grain fall 
to the bottom of the person and straw weed seed and broken grain are carried by the wind to a distance. For better results the person should stand on a height. In most cases results are not satisfactory after this activity so minute wheat cleaning is done by hand picking by women (Baloch, 1999).

Cleaning and grading are the important operations of primary processing of agriculture produce, undesirable foreign materials like dirt, dust, leaves, trashes, stones, sand etc. are removed from the produces during cleaning operations. Cleaning operation is carried out manually either by winnowing or hand sieves. It is laborious, time consuming \& moreover, it is costly.

After harvesting severe processing to remove unwanted things are required eg seeds of noxious weeds, after crop/variety seed, decorticated seeds damaged and unequal seeds. This will result is reduced bulk of seeds, high value product, safe and longer storage and better quality of product.

There is no doubt that women in developing countries spend much time and energy in poorly remunerated, repetitive crop handling and food cleaning processing activities.

Ergonomics as a science is defined to solve the problem and to help the farm women to work is better condition for which efforts of scientists are required. Ergonomics is branch of science that work for easing the task of farm women by equipment, knowledge and surroundings that will suit each worker (Rajendran and Reddy, 2013).

Grain cleaning and grading for women in rural area is a big problem because they use traditional sieve for cleaning and grading manually in sitting posture. This posture increases the fatigue and drudgery of farm women while cleaning and grading which results in aches and pains in the back and cervical region. This is time consuming method and output realized is less. Keeping this in mind KVK-Ratlam intervened with developing intention that hanging grain cleaner may be the answer to reduce the drudgery and increase work output.

Hanging grain cleaner is an important machine especially designed for wheat cleaning and grading. The machine is operated by hands to sieve the grain batches of $5-10 \mathrm{~kg}$ and clean.

The machine parts consist of main frame, scalper/grading screen, draper rod, handle, shutter etc. It is hanged by eyelets at the top so weight of machine doesn't come to arms of worker. Once filled, it removes the impurities from grain by swinging action.

This paper is based on the works done by KVK-Ratlam in introducing a Hanging Grain Cleaner, a drudgery reducing implement. Hanging Grain Cleaner is an important machine especially designed for wheat cleaning and grading.

The aims of present study was

To examine working of hanging grain cleaner over traditional grain cleaning.

To examine the ergonomic parameters on hanging grain cleaner to reduce fatigue of workers.

To examine exertion by farm women in both methods by overall discomfort rating (ODR).

\section{Materials and Methods}

Thirty farm women who were healthy and with no physical aliment were selected from Richha deveda and Chiklana, two villages of KVK Ratlam, Madhya Pradesh, India. They had good experience of control and operating 
traditional sieve method. The BMI score of all the thirty women was done as per Garrow (1987) classification. Each farm women was tied heart rate monitoring machine to record the heart rate at every minute. The heart rate of worker was noted at every minute when they were asked to do work for 30 minutes. Then a rest of 5 minutes was given and again the heart rate at rest was noted. Now the heart rate monitor was switched off and removed. Heart rate during rest, work and recovery was noted in both traditional and hanging grain cleaner. Based on the heart rate records the following parameters were calculated -

Average heart rate during rest and work.

$\Delta \mathrm{HR}$ (beats $/ \mathrm{min})=$ Average working heart rate (WHR) - Average heart rate during rest.

For calculation of Energy Expenditure Rate from heart rate, the Varghese (1994) equation was used which is as follows.

$\operatorname{EER}(\mathrm{kj} / \mathrm{min})=0.159 * \mathrm{HR}($ beats $/ \mathrm{min})-8.72$.

Output $=$ kg/hour

Overall discomfort rating (ODR) was taken on a 10 point psychophysical rating scale $(0=$ no discomfort, $10=$ extreme discomfort) which is an adoption of Corlett and Bishop (1976) technique.

Total cost of work (TCCW) and Physiological cost of work (PCW) were determined by using the average heart rate during rest at work, recovery and duration of work.

Total cardiac cost of work Physiological cost of work =

Duration of work (min)

Total cardiac cost of work $(\mathrm{TCCW})=$ Cardiac cost of work $(\mathrm{CCW})+$ Cardiac cost of recovery $(\mathrm{CCR})$
$\mathrm{CCW}=$ (Average working heart rate Average resting heart rate) $*$ Duration of work (min)

$\mathrm{CCR}=$ (Average recovery heart rate Averaged heart rate)* Duration of recovery (5 $\min )$

Cardiac cost of worker per unit of output (beats $/ \mathrm{kg})=\Delta \mathrm{HR} *$ duration/output.

\section{Classification of workload}

Varghese in 1994 classified workload of activity in different occupation shown in Table 1 .

\section{Overall Discomfort Rating (ODR)}

Overall discomfort rating (ODR) had been defined by using a 10 point psychophysical rating scale. There was a movable pointer on it. After each experience subjects indicated the comfort level on this scale (Fig. 1). At the end of the each trial averages of overall discomfort rating values had been calculate.

Overall discomfort rating (ODR) was assessed by using the scale used which was developed by Corlett and Bishop (1976) for the assessment of it. It consisted of a $70 \mathrm{~cm}$ long graduated scale with its left marked as 0 and right 10 which are representing 'no discomfort' and 'extreme discomfort', respectively. A sliding pointer was provided on the scale to mark the level of discomfort. At the end of each trial subjects was asked to mark their overall discomfort rating on the scale. The overall discomfort rating given by each of the thirty subjects was averaged to get the mean rating (Sam and Kathirvel, 2008).

\section{Rating of perceived exertion}

Pain is the indicator of discomfort. The perceived discomfort was recorded in terms of 
pain felt in different parts of the body by the subjects while performing the activity. The Rating Exertion scale development was used to subjectively assess the exertion perceived.

The experiment was conducted at different time intervals of the day between 9:00 AM and 5:30 PM. The trials were given in randomized order to minimize the effects of extraneous factors.

Each subject had a rest for 15 minutes before starting trial. Subjects were asked to indicate ODR and perceived exertion assessments after working period. The same procedure was repeated three times for all the selected subjects.

Drudgery can be defined as physical \& mental strain, fatigue, monotony and hardship experience by farm women while doing weeding operations (Kumar et al., 2011).

\section{Results and Discussion}

Physical characteristics of the respondent: Basic anthropometric data of the subjects have been presented in Table 2. As shown in the table, the average age of the selected thirty farm women was 32.2 years. The average height was $165.9 \mathrm{~cm}$. and the gross body weight was $56.9 \mathrm{~kg}$. The mean body mass index was 21.9 indicating that they were normal.

Workload: During activity the classification of workload, as discussed before, was done on the basis of average heart rate and average energy expenditure.

The activity was heavy while using hanging grain cleaner and moderate while using traditional sieve but the women worked with comfort while using hanging grain cleaner and at a faster rate also hanging grain cleaner was or proved be a better implement. It could be observed that Table 3 show that majority of the respondents $(70.0 \%)$ were in normal category with regard to BMI Scores, $6.7 \%$ of women had BMI Scores in obese grade I range and $23.3 \%$ women were in the range of low weight normal category.

Physiological workload: Analysis of data Table 4 shows that workload as heart was less and energy expenditure was reduced with the use of hanging grain cleaner. Hanging grain cleaner proved efficiency in time consumption and output parameters as compared to traditional sieve method.

With the use of hanging grain cleaner the average working heart rate was reduced to 8.15 percent and energy expenditure was also reduced. In table 4 the results clearly indicate that improved technology has significantly higher work output than the tradition al method.

\section{Output}

The results presented in Table 4 depict the work output of the cleaning activity with the traditional and improved technologies. Improved technologies have significantly higher work output than the traditional technology.

Maximum increased work output was observed by using the hanging grain cleaner. The output capacity was higher using hanging grain cleaner $(129.7 \mathrm{~kg} / \mathrm{hr})$ as compared to only $(70.2 \mathrm{~kg} / \mathrm{hr})$ with traditional sieve.

The percentage increase is work output was 84.7 for hanging grain cleaner which is repeat as compared to traditional method.

So by adopting this improved technology for cleaning and grading activity, the farm women can increase their efficiency, increase work output and reduce the drudgery. 
Fig.1

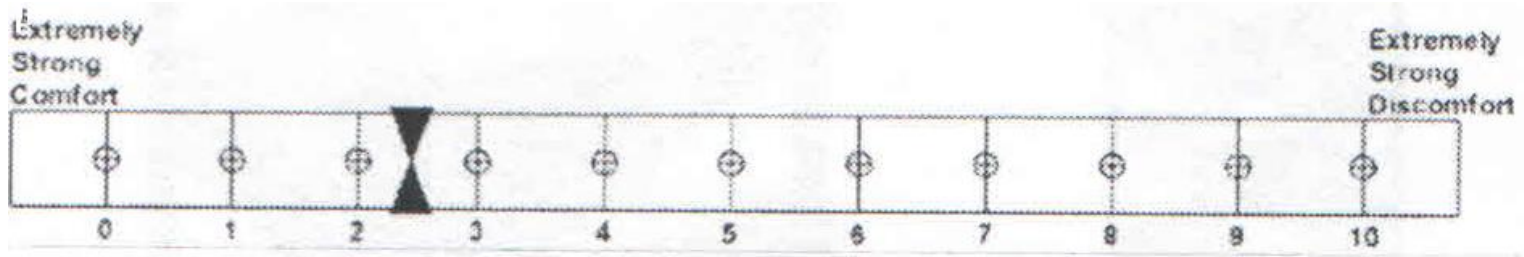

Figure B. Overall Discomfort Rating Scale

Fig.2

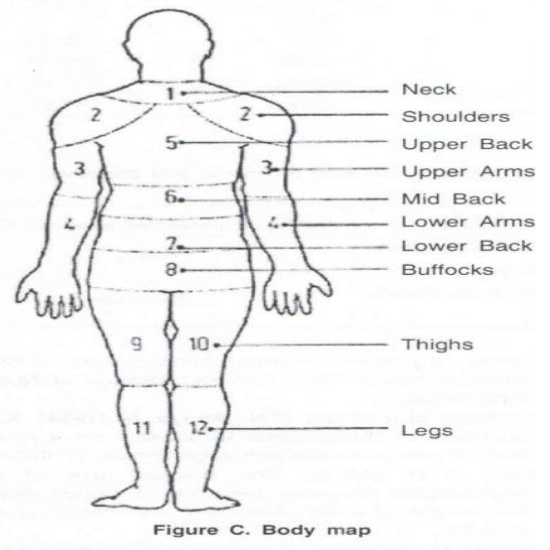

Table.1 Classification of Workload

\begin{tabular}{|l|}
\hline Physical work load \\
\hline Very light \\
\hline Light \\
\hline Moderate \\
\hline Heavy \\
\hline Very heavy \\
\hline
\end{tabular}

Extremely heavy

\section{Physiological variables}

\section{Energy expenditure (KJ/Min)}

Upto 5.0

5.0-7.5

7.6-10.0

$10.0-12.5$

$12.6-15.0$

\section{$<15.0$}

\section{Heart beats (beats/min)}

Upto 90

91-105

106-120

\section{1-135}

$136-150$

\section{Above 151}

Table.2 Physical characteristics of the respondent $(\mathrm{N}=30)$

\section{Physical characteristics}

\begin{tabular}{|l} 
Age in years \\
\hline Height $(\mathrm{cm})$
\end{tabular}

Height (cm)

Gross weight in kg

Body Mass Index

\begin{tabular}{|l|l|}
\hline Range & Mean \\
\hline $21-45$ & 32.2 \\
\hline $141-180$ & 165.9 \\
\hline $42-70$ & 56.9 \\
\hline $18.9-26.3$ & 21.9 \\
\hline
\end{tabular}


Table.3 As shown in the table Distribution of respondents as per BMI scores. $(\mathrm{N}=30)$

\begin{tabular}{|l|l|l|}
\hline BMI Scores & Interpretation & $\%$ \\
\hline$<16.0$ & *CED grade lll (severe) & - \\
\hline $\mathbf{1 6 . 0}-\mathbf{1 7 . 0}$ & *CED grade ll (moderate) & - \\
\hline $\mathbf{1 7 . 0 - 1 8 . 5}$ & *CED grade 1 (mild) & - \\
\hline $\mathbf{1 8 . 5}-20$ & Low weight normal & $23.3 \%$ \\
\hline $\mathbf{2 0 . 0 - 2 5 . 0}$ & Normal & $70.0 \%$ \\
\hline $\mathbf{2 5 . 5}-\mathbf{3 0 . 0}$ & Obese grade 1 & $6.7 \%$ \\
\hline $\mathbf{3} 30.5$ & Obese grade ll & \\
\hline
\end{tabular}

Table.4 Change in heart rate, energy expenditure and output by use of Hanging Grain Cleaner over traditional sieve $(\mathrm{N}=40)$

\begin{tabular}{l} 
Parameter \\
Number of worker required \\
Output, Kg/hour \\
Quantity of seed per/ batch, $\mathrm{kg}$ \\
\hline Av.resting heart rate, beats/min \\
\hline Av.working heart rate beats/min \\
\hline Av. Energy expenditure resting, $\mathrm{Kj} / \mathrm{min}$ \\
\hline Av. Energy expenditure working, $\mathrm{Kj} / \mathrm{min}$ \\
\hline$\Delta$ HR (beats/min) \\
\hline Cardiac cost (beats/min) \\
\hline Total cardiac cost of work (TCCW) \\
\hline Physiological cost of work (PCW) \\
\hline$\%$ reduction in drudgery \\
\hline$\%$ increase in efficiency \\
\hline
\end{tabular}

\begin{tabular}{|c|c|c|}
\hline $\begin{array}{c}\text { Traditional } \\
\text { Seise }\end{array}$ & $\begin{array}{l}\text { Hanging grain } \\
\text { cleaner }\end{array}$ & $\begin{array}{c}\text { \% change in improved } \\
\text { over existing }\end{array}$ \\
\hline 01 & 01 & - \\
\hline 70.2 & 129.7 & $\uparrow 84.7 \%$ \\
\hline 1.9 & 8.5 & - \\
\hline 73.0 & 73.8 & $\uparrow 1.09 \%$ \\
\hline 115.4 & 106.7 & $\downarrow 8.15 \%$ \\
\hline 2.88 & 3.01 & $\uparrow 4.51 \%$ \\
\hline 9.62 & 8.24 & $\downarrow 16.7 \%$ \\
\hline 42.4 & 32.9 & $\downarrow 28.8$ \\
\hline 36.2 & 15.2 & $\downarrow 138 \%$ \\
\hline 956 & 841 & $\downarrow 13.6 \%$ \\
\hline 15.9 & 14 & $\downarrow 13.5 \%$ \\
\hline- & - & $\downarrow 58 \%$ \\
\hline- & - & $\uparrow 84.7 \%$ \\
\hline
\end{tabular}

$\uparrow$ indicates\% increase $\downarrow$ indicates $\%$ decrease.

Table.5 Overall discomfort rating (ODR)

\begin{tabular}{|l|l|l|l|}
\hline Technique & ODR & MSP & RPE \\
\hline Traditional Seive & 7.12 & Severe pain in shoulders, upper back, hands and fingers & Heavy \\
\hline Hanging grain cleaner & 4.46 & Moderate to light pain in shoulder, hands and arms. & Moderate \\
\hline
\end{tabular}

\section{Overall discomfort rating (ODR)}

Cleaning of wheat activity is time taking as it is performed for hours together continuously. Because of this activity the musculo-skeletal problems are leading encountered. Due to continuous sitting posture, the results observed with overall discomfort rating are presented as shown Table 5.

Table 5: Mean value of overall discomfort rating (ODR), Responses on muscularskeletal problems and perceived exertion experienced by respondents 


\section{Musculo-skeletal problems}

Musculo-skeletal problems and posture were evaluated by asking the respondents as to where they felt pain in their body after cleaning with traditional and improved technology. Table 5 depicts that working in a particular posture for longer duration of time causes fatigue and maintaining same posture beyond certain limit of time for years causes musculo-skeletal disorders in the body.

As a result, the working efficiency of the workers is greatly reduced. Working in squatting posture for longer period might be the reason that almost all the woman reported severe to moderate discomfort in lower back, knees, upper back, ankle knees, feet and neck. So the women perceived the task as a heavy are On the other hand by using hanging grain cleaner they felt light discomfort/pain in shoulder, hands and arms and there was no back pain. By working with hanging grain cleaner Sitting posture was eliminated and some body movements were also there so the exertion was less.

\section{Implication of the study}

During wheat cleaning and grading for long hours women usually adopt squatting posture. It leads to severe pain in lower back and knee. Farm women are the backbone of agriculture but they are not aware of the latest technological breakthrough in agriculture. Women should be educated about the benefits of such implements in terms of reducing their drudgery and increased work output. Women are trained in the new agricultural tasks they perform, including the safe use and maintenance of agricultural machinery so that their productivity is enhanced. Rural artisans need to be encouraged for the development of cost effective prototype of the improved farm implements and also for the repair and maintenance of the improved equipments.
This will facilitate the easy accessibility of farm equipments for farm mechanization.

The ideal work equipment should ensure health safety and wellbeing of the person. So it is essential that working equipment should be designed ergonomically and it should be user friendly. Hanging grain cleaner is ideal for work as it increase the work efficiency and reduce drudgery by avoiding bending and squatting posture. So farm women feel comfortable and they earn more money by reducing the labour engagement during cleaning of wheat. Money beings happiness in their families and their social life also improves.

Effort has also been made to provide training to women extension functionaries and farm women for skill up gradation on these tools and equipment. Making these tools available in rural area is also very important and needs to be given due consideration. Use of these technologies will enables the farm women to have more earning and also to reduce their drudgery in various field operations

\section{References}

Corlett E.N. and Bishop, R.P. 1976. A Technique for assessing postural discomfort, Ergonomics, 19,175-182

Garrow J 8.1987. Human Nutrition and Dietetics. Nutrition News 1991. National Institute of Nutrition, Hyderabad.

Kumar Bharat. P.P., Govinda Gowda.V. and Neeta Khandekar. 2011. Time utilization pattern and drudgery of horticulture farmers. International Journal of Engineering \& Management Sciences. 2(2): 93-96.

National seminar on women farmer - NSWF February 2014. Organized by Junagadh Agricultural University, Junagadh, (Gujarat), Vigyan Prasar, 
Department of Science and Technology, NOIDA (UP) and National Council for Climate Change, Sustainable Development and Public Leadership, Ahmedabad, (Gujarat).

Rajendran Poornima and Lokanadha Reddy 2013. Ergonomics in Agricultural Education, Cognitive Discourses International Multidisicplinary Journal ISSN 2321-1075 Volume 1, Issue 1, July.

Sam B. and Kathirval K. 2008. Assessment of Postural Discomfort during Power Tiller Operation. Agricultural Mechanization in Asia. Africa and Latin America
39(1): 14-23. Japan.

Suma Hasalkar Shobha Huilgol Medha Hosakeri P. Kavita Chhayadevi A. Badiger 2005. Evaluation of workload of farm women in various agricultural activities. Karnataka J.Agric.Sci., 18(3):865-868.

Uma K. Baloch. 1999. Wheat: Post-harvest operations. Pakistan Agricultural Research Council (PARC)

Varghese M.A., Saha P.N., Atreya N. 1994. A rapid appraisal of occupational workload from a modified scale of perceived exertion. Ergonomics, 37, 485-491.

\section{How to cite this article:}

Barkha Sharma, Shilpi Verma, S.K. Pandey and Jagdish Patidar. 2018. Drudgery Reduction for Increasing Efficiency of Farm Women Using Hanging Grain Cleaner: A Case of Eco-friendly Method in Wheat Cleaning and Grading. Int.J.Curr.Microbiol.App.Sci. 7(01): 1600-1607. doi: https://doi.org/10.20546/ijcmas.2018.701.194 